\title{
A TRADUÇÃO DA LOGOPEIA: POUND, HAROLDO E OVÍDIO
}

\section{THE TRANSLATION OF LOGOPEIA: POUND, HAROLDO AND OVID}

\author{
Brunno V. G. VIEIRA ${ }^{1}$
}

RESUMO: Pretende-se fornecer uma análise de algumas passagens do episódio da "Morte de Narciso" das Metamorfoses(3.407-510), de Ovídio, na tradução de Haroldo de Campos. Parte-se, para tanto, da formulação da logopeia de Ezra Pound (1971), que foi cunhada por ele em uma resenha sobre a poesia de Mina Loy, e se verificam as potencialidades e, também, as variações que esse conceito recebe na teoria e na prática tradutória de Campos.

PALAVRAS-CHAVE: Tradução; Ovídio, Haroldo de Campos; Ezra Pound; logopeia

ABSTRACT: This paper aims to analyze some excerpts of "The death of Narcissus" by Ovid'sMetamorphoses (3.407-510), translated by Haroldo de Campos. For this purpose, Ezra Pound's formulation of logopoeia, created by him in a review about Mina Loy's poetry, is used in order to verify the potentialities and the variations which this concept bears in Haroldo de Campos'translation practice and theory.

\footnotetext{
${ }^{1}$ Departamento de Linguística, Faculdade de Ciências e Letras (câmpus Araraquara), Universidade Estadual Paulista "Júlio de Mesquita Filho", CEP 14.800-901, Araraquara, São Paulo, Brasil. E-mail: brvieira@fclar.unesp.br
} 
KEYWORDS: Translation; Ovid; Haroldo de Campos; Ezra Pound;logopeia.

Trato aqui de um modo particular de interpretar - seja sob viés analítico, seja sob viés tradutório - a poesia latina clássica hoje. Ocupo-me da logopeia de Ezra Pound, ou seja, da "dança da inteligência" - na definição de 1918 - ou "a dança do intelecto entre palavras" - no conceito definitivo de 1928, a fim de compreender o uso que Haroldo de Campos dela faz, especialmente na sua abordagem tradutória dos poetas da Roma Antiga. À guisa de exemplificação das potencialidades e das variações operadas no conceito, desde Pound até sua apropriação haroldiana, ofereço uma leitura de alguns versos sobre Narciso, extraídos das Metamorfoses de Ovídio e traduzidos por Haroldo de Campos ${ }^{2}$.

Em “dança do intelecto"entrevejo a linha dos sentidos do poema, o verso, aquilo que corre ou transborda, que segue palavra após palavra na sequência rítmica entre pausas. Estou pensando nas relações de combinações no eixo sintagmático lembradas por Jakobson (1969, p.129-30), que revelam o progresso dos sentidos por meio da combinatória dos vocábulos. Mas "dança do intelecto" não é só sentido, porque estamos falando de poesia, sequência de palavras das quais o eixo de seleção é indissociável, como está, aliás, presentificado na segunda parte da definição de Pound "dança do intelecto entre palavras" (POUND, 1976, p.37, grifo meu). Não basta em poesia o sentido do que sucede. As palavras ausentes também significam. Todas que poderiam entrar e, no entanto, permaneceram do lado de fora do poema.

0 próprio Pound busca precisar mais prosaicamente essa metáfora:

[a logopeia se dá] pelo emprego das palavras não apenas por seu significado direto, mas levando em conta, de maneira especial, os hábitos de uso, do contexto que esperamos encontrar

${ }^{2}$ Uma primeira versão deste texto foi apresentada oralmente na "Jornada do Projeto de Extensão Olhares de versos: Leitura, Estudo e Divulgação de Poesia”, realizada no IBILCE/UNESP em 28/11/2012. 
com a palavra, seus concomitantes habituais, suas aceitações conhecidas e os jogos de ironia (POUND, 1976 [1928], p. 378). ${ }^{3}$

Pound cunhou o termo logopoeia em uma resenha de 1918, dedicada à poeta anglo-americana Mina Loy (1882-1966). À época da resenha, Pound o define como "poesia que não é nada senão linguagem, que é a dança da inteligência entre palavras e ideias e modificação de ideias e personagens" (1918, p. 57) ${ }^{4}$. Permito-me - permitam-me - um pequeno excurso introdutório para apresentar um dentre os vários poemas de Mina Loy publicados na revista Others e que motivaram a análise de Pound, para vislumbrarmos na prática sua concepção sobre essa espécie de poesia em sua mais prisca aparição:

\author{
IX \\ When we lifted \\ Our eye-lids on Love \\ A cosmos \\ Of coloured voices \\ And laughing honey \\ And spermatozoa \\ At the core of Nothing \\ In the milk of the Moon \\ (LOY, 1996, p. 56) \\ quando elevamos \\ nossas pálpebras - amando - \\ um cosmos \\ de matizadas vozes \\ de ridente mel
}

\footnotetext{
${ }^{3}$ Esta definição é praticamente a mesma que foi estampada no $A B C$ da Literatura: "assumimos o risco ainda maior de usar a palavra numa relação especial ao 'costume', isto é, ao tipo de contexto em que o leitor espera ou está habituado a encontrá-la. Este é o último método a desenvolver e só pode ser usado pelos sofisticados. (Se vocês querem realmente compreender do que eu estou falando, têm de ler, afinal, Propércio e Laforgue)"(POUND, 1970 [1934], p. 41).

${ }^{4}$ Quando não explicitada a fonte, são minhas as traduções.Como este é um texto de difícil localização, transcrevo-o em inglês: Poetry that is akin to nothing but language, which is a dance of the intelligence among words and ideas and modification of ideas and characters.
} 
e espermatozóides

ao âmago do Nada

no leite da Lua

No caso de Mina Loy, há o contexto das livres associações -, recurso caro ao Expressionismo de uma poetiza que também flerta com o Dadaísmo e com o Surrealismo -, todas essas tendência efervescentes no período em que esses versos vieram à luz, ou seja, na segunda década do século XX. As palavras estabelecem-se como linguagem pela sucessão das unidades vocais na sequência discursiva do poema, mas saltam aos olhos as obstruções da linearidade dos sentidos que obrigam o leitor a fazer dançar sua inteligência.

0 que prevalece é o baile entre a ideia e sua disposição, irrompendo os concomitantes habituais. Vide a inversão entre coloured e laughing modificando inusitadamente voices e honey, quando o mais previsível seria o mel colorido (coloured honey) e as ridentes vozes (laughing voices). Vide o jogo notável vindo do irônico choque entre Amor sublime(Love em maiúscula) e Cosmogonia (a cosmos)com uma voraz cena de sexo, de olhos abertos (liftedoureye-lids), cheia de gemidos (voices/laughing) e secreções (honey/spermatozoa/milk).

Se listarmos os substantivos do poema(eye-lids, love, cosmos, voices, honey, spermatozoa, core, Nothing, milk, Moon) é possível ver a alternância entre o táctil concreto (ou corpóreo) em relação à abstração conceitual. É possível ver a alteração de sentido principalmente em direção ao erotismo provocada pelas sequências de ideias que subvertem seu lugar no discurso: Love (o Amor), pulsão cosmogônica primordial, termina em Nothing (Nada) - como que dimensionado pelos limites entre coito e orgasmo -, depois de spermatozoa como ler milk, como ler honey em face de Moon (lua de mel/honeymoon). 0 encadeamento dos signos revela uma lúbrica e desconcertante coreografia.

Sirvo-me do poema de Mina Loy para exemplificara logopeia na mais instantânea acepção dada por Pound a essa espécie de poesia. Peter Ni- 
cholls (2002) que recentemente estudou a influência de Loy em Pound sugere que "o exemplo de logopeiano trabalho de Loy foi o que permitiu Ezra Pound desenvolver uma teoria crítica que poderia justificar e explicar sua recente publicação de Homageto Sextus Propertius[1919]" (2002, p. 54). Assinalo, então, o fim dessa digressão com um dispositivo logopeico como é a comparação: Pound desloca um recurso flagrado na poesia moderna para reconhecê-lo na poesia antiga, como Haroldo de Campos usará a logopeia que encontrou em Pound para ler e traduzir as obras dos poetas latinos.

Um exemplo do Propércio de Pound cotejado por Haroldo pode fazer bem a essa transição entre o insight poundiano e sua singular apropriação haroldiana, seara da tradução de poesia latina que nos transportará ao cerne deste artigo.

Propércio é um poeta elegíaco latino da segunda metade do século I a.C. A elegia em Roma mereceu um grande desenvolvimento principalmente em sua temática amorosa com suas primícias em Catulo e seu desenvolvimento em Propércio, Tibulo e Ovídio. Propércio canta seus amores à sua musa Cíntia, quando o Império Romano demandava uma epopeia para cantar seus feitos bélicos. Pound o traduz atualizando o mesmo contraste político em relação ao Império Britânico na opinião de seus críticos (DAVIDSON, 1995, p.83-84).

Em um importante artigo de 1987, Da transcriação: poética e semiótica da operação tradutora, no qual Campos traça uma autobiografia de seus exercícios teóricos e práticos de tradução até aquele momento, há uma referência a um verso de Propércio, traduzido por Pound e reinterpretado por Haroldo de Campos. Essa citação lança luz sobre como o poeta brasileiro trasladava o conceito de logopeia e sobre possíveis maneiras de transpô-la poeticamente em português: 
"utquedecempossintcorrumpere mala puelas

(e como dez maçãs possam perverter as jovens)

Pound, não resistindo à oportunidade do trocadilho, traduziu 'maçãs' (malum, i) pelo homófono que significa 'má ação', 'vício' (também neutro com o plural em -a), e escreveu:

And how ten sins can corrupt young maidens

(E como dez pecados podem corromper donzelas).

$\mathrm{Ou}$, como eu gostaria de retraduzir, aproveitando a 'deixa' e extremando o exemplo:

'E como dez más ações - maçãs, má sina! podem perverter meninas',

Já que o trocadilho semântico de Pound parece ter sido guiado (...) pelo jogo fônico entre DEcEMpoSSINt e TEN SINS...

(CAMPOS, H., 1987, p.55-56)

Notemos que a flagrada essência da logopeia reside no trocadilho que se pode sacar do texto de Propércio. Do ponto de vista filológico, a tradução de mala por "más ações" (ou sins) pode ser considerada a priori errada, mas o valor máximo da palavra mala reside no estranhamento potencial flagrado na sucessão de palavras latinas e por aquilo que, estando ausente em uma das interpretações lineares possíveis (maçãs ou malefícios?), não escapava ao leitor que lia/lê Propércio em latim. A solução tradutória de Haroldo de Campos, neste caso, é atualizar sintagmaticamente em parole o eixo paradigmático (langue) ao leitor lusófono com “maçãs, má sina”, propondo, assim, um equivalente à difícil tradução dessa espécie de poesia que é a logopeia:

[ela] não se traduz; não obstante, a atitude mental por ela expressa pode passar por uma paráfrase. Ou, pode-se dizer, você não a pode traduzir "localmente", mas, tendo determinado o estado de espírito original do autor, você poderá ser ou não capaz de encontrar algum derivado ou equivalente (CAMPOS, 1976, p.38).

Sabemos da importância que o paideuma poundiano exerceu sobre 
Campos e sobre os poetas do seu grupo. ${ }^{5}$ Entre os latinos, além de Propércio, também Catulo, Horácio e Ovídio são os poetas que interessavam a Pound, porque, segundo recorte iconoclasta do fabbro, eles podiam trazer uma contribuição efetiva para poesia do presente. Em Crisantempo, por exemplo, Haroldo de Campos publica traduções de Catulo, Horácio, Pérsio e de um encorpado excerto de Ovídio, denominado A morte de Narciso. Toda essa seleção segue, quase ao pé da letra, o cânone latino ditado por Pound ${ }^{6}$ e citado expressamente em uma nota em que o tradutor também externa o seu critério para as versões dos poemas latinos, nestes termos: "há uma preocupação marcante com a 'logopeia', a 'dança do intelecto entre as palavras'”' (cf. CAMPOS, H., 1998, p.360).

Com base nas formulações da logopeia poundiana e na expressa declaração de Campos sobre seu uso na tradução de poetas latinos, passo a tratar do excerto $A$ morte de Narciso que é, ainda me parece (VIEIRA, 2006, p.84), a tradução mais acabada entre os "Latinórios" e, talvez, a contribuição mais madura de Haroldo de Campos durante o domínio latino.

0 episódio das Metamorfoses de Ovídio é aquele em que o jovem Narciso, embevecido da própria beleza refletida na água de uma fonte, mata-se na tentativa de possuir-se. Embora a mítica narrativa seja bas-

\footnotetext{
${ }^{5} 0$ exemplo do paideuma de Pound deu vigor programático aos anseios propositivos do grupo Noigandres que encontrou, na reelaboração da tradição, a melhor forma de revêla. Afirmar isso não significa que o avançado recuo à tradição exercido por Campos seja unicamente debitário a Pound. Diana Martha-Toneto (2012) oferece uma interessante e produtiva reflexão sobre uma possível dicotomia entre um projeto coletivo do grupo concretista e um projeto individual de Haroldo de Campos, que parece (re)definir bem as motivações fáusticas que esse recuo ao trabalho de Ovídio, e aos poetas latinos no geral, representa. Lendo o artigo Uma metamorfose que introduz o episódio de Ovídio em sua primeira publicação na Folha de São Paulo (CAMPOS, H., 1994, p.6-6), é possível entrever essas motivações fáusticas de que fala Diana Martha-Toneto, uma vez que Haroldo cita, como importantes provocadores de seu Narciso, poetas de diferentes linhagens e vertentes estéticas como Pound, Valéry e Lezama Lima, evocando certo barroquismo de Ovídio que certamente não fazia parte da interpretação poundiana do poeta latino.

${ }^{6}$ Cito a íntegra da referência a Pound: "A série catuliana remonta (com revisões posteriores) a 1971, quando esbocei um projeto de tradução de alguns carmina do extraordinário poeta latino (século I a. C.), para uma edição a cargo de Cleber Teixeira, com uma epígrafe de Pound: Catullus, Propertius, HoraceandOvid are thepeoplewhomatter. Catullusmost(CAMPOS, H., 1998, p.360)"
} 
tante conhecida entre nós contemporâneos, a ponto de usarmos muito corriqueiramente o adjetivo "narcisista", o conteúdo dessa narrativa não chega aos pés - para usarmos uma expressão igualmente cotidiana - da forma poética pela qual Ovídio lhe expressa.

Trata-se de 103 hexâmetros latinos (Met. 407-510) vertidos em iguais 103 dodecassílabos. 0 metro adotado em português para verter os versos de Ovídio é o mesmo que Haroldo tinha usado em 1992 no excerto do canto primeiro da Ilíada publicado na Revista da USP e que viera a lume no livro MÊNIS ou A ira de Aquiles também de 19947, mesmo ano da publicação de $A$ morte de Narciso no caderno Mais! do jornal Folha de São Paulo em 21.08.1994. Segundo Campos, o dodecassílabo é "a medida mais apta para a transposição do hexâmetro" (CAMPOS, H., 1999, p.112), por ser o maior metro fixo do português, exceptuando-se o experimento do hexâmetro português de Carlos Alberto Nunes, que já nos habituamos a chamar de verso núnico (FLORES, 2011, p.145-146). Essa escolha métrica haroldiana tem sido amplamente adotada em traduções poéticas contemporâneas do hexâmetro (seja em grego, seja em latim) para o português.

Estamos, então, diante de um Haroldo de Campos septuagenário retomando um verso que praticou pela primeira vez no seu livro de estreia, O auto do processo (1950), em poemas como "Sinfonia dos Salmos" e "Lamento sobre o lago de Nemi”(cf. CAMPOS, H., 1976, p.18-19; p.23). Mas o dodecassílabo desses traslados greco-romanos da maturidade traz em si o peso e o itinerário de uma carreira inteira vivida sobre a palavra. Uma carreira que tanto denegou o verso como, empregando-o, soube carregá-lo do máximo grau de poesia.

0 objetivo da recriação dos hexâmetros é declarado no prefácio de sua tradução homérica: "estou empenhado em recriar, em nossa língua, quanto possível, a forma de expressão (no plano fônico e rítmico-prosódico) e a forma de conteúdo(a 'logopeia', o desenho sintático, a 'poesia da gramática')" (CAMPOS; VIEIRA, 1994, p.14). Nesta declaração, parece-

${ }^{7}$ Essa forma métrica seria usada para verter a Ilíada de Homero integralmente (2002). 
me claro que o conceito de logopeia com o qual Campos trabalha já não é exatamente aquele de Pound - ou melhor, sem ser excludente, não é só aquele de Pound -, pois o transcriador está preocupado com equivalentes métricos e mesmo com decalques de desenhos sintáticos da língua de chegada na língua de partida, algo a que as ideias de tradução de Pound não se conformam cabalmente. Há, nessa definição de "forma

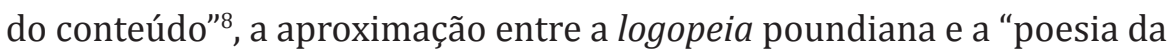
gramática" de Jakobson (1969) que justifica o trabalho atento de Haroldo de Campos em relação a paralelismos sintáticos e métricos da poesia de Ovídio.

Além disso, logopeia, na tradução de línguas antigas, envolve também intromissões sintáticas (latinizantes e greicizantes) que eram caras a um Odorico Mendes, por exemplo ${ }^{9}$.Assim, o que Haroldo faz já não é apenas o "Make it New" poundiano. Aglutinadas a este pensamento ${ }^{10}$, sobrepõem-se ideias formalistas de Jakobson e um viés literalizante em tradução, na esteira de Filinto Elísio, Odorico Mendes e dos românticos alemães (estes que fundamentaram Benjamin). Tudo resultando naquele, a meu ver, definitivo postulado de tradução haroldiana: "sempre de acordo com a minha teoria (e minha prática), de mais de trinta anos, segundo a qual a hiper fidelidade fono-sintático-semântica em tradução de poesia só se obtém através de uma liberdade multidisciplinada" (CAMPOS, H. 2010 [1993], p.187).

Na recriação de Narciso, parece imprescindível a Campos uma forma

${ }^{8}$ Forma da expressão e forma do conteúdo são conceitos de Hjelmslev aplicados mais ou menos sistematicamente à tradução ( cf. LOPES, 1980, p.94-6 e especialmente à tradução de poesia latina cf. PRADO, 1997, p.169 e LIMA, 2003, p.107). Para uma reflexão.

${ }^{9}$ Segundo penso, esta crítica de Pound aos tradutores ingleses do grego, que reproduzo abaixo, poderia ser muito bem estendida ao nosso Odorico Mendes, o que resultaria em uma consistente divergência entre Pound e Haroldo. Cf.: "Parece-me que os tradutores ingleses se perderam em dois pontos, primeiro tentando manter cada adjetivo, quando obviamente muitos adjetivos no original têm apenas valor melódico; segundo ficaram aturdidos pela sintaxe; perderam tempo, comprometeram seu inglês, tentando primeiramente promover uma estrutura lógica limitada para o grego e, depois, tentando preservá-la em inglês, e a todas as suas relações gramaticais" (POUND, 1960, p.273).

${ }^{10}$ Achar que apenas as ideias de Pound definiriam as práticas de Haroldo, fidelidade que Jorge Wanderley (apud MILTON, 2010, p.236) parece esperar, é, de fato, um equívoco. 
métrica fixa que corresponda ao hexâmetro ${ }^{11}$ e, ao mesmo tempo, uma preocupação com a expressão de uma equivalência no nível sintagmático dos concomitantes habituais de cunho mais propriamente poundiano. A se considerar esse método híbrido e complementar, a vivência do tradutor-poeta e sua maturada sensibilidade formal serão fundamentais para o resultado convincente de suas escolhas tradutórias que passo a apontar.

Vou analisar, a seguir, alguns pares de versos a fim de ilustrar a prática haroldiana de transposição logopeica.

Hic puer et studiovenandilassus et aestu

Procubuit, faciemque loci fontemquesecutus.

(Ov. Met. 3.413-4) ${ }^{12}$

Da caça e do calor exausto, aqui vem dar

Narciso, seduzido pela fonte amena.

Se inclina.

(Tradução do conteúdo) Aqui o rapaz deitou, tanto cansado pela dedicação à caça como pelo calor, perseguindo a beleza do local e a fonte.

Pensando no texto latino, o essencial da logopeia é o enjambement que lança abaixo o verbo latino procubuit, literalmente, "se deita". O verso desce um degrau assim como Narciso (hic puer) se abaixa. A disposição da palavra no verso encena o movimento de seu conteúdo, tal qual tento evidenciar com a disposição gráfica que segue:

\footnotetext{
${ }^{11}$ Neste ponto de decisão pelo metro fixo, parece haver bastante influência de Jakobson: "são muitas vezes os contrastes na estrutura gramatical que servem de apoio à divisão métrica de um poema em estrofes e segmentos menores[...]. Tais contrastes podem até mesmo funcionar como alicerces de uma composição em strata" (1970, p. 73).

${ }^{12}$ A tradução, seja na primeira versão em jornal (CAMPOS, H., 1994), seja na publicação em livro (CAMPOS, H., 1998), aparece em formato monolíngue. Tomo o texto latino de Chamonard (OVIDE, 1936), já que Haroldo de Campos faz menção a essa edição na introdução à tradução por ocasião de sua publicação em jornal.
} 
VIEIRA, B. V. G. A tradução da Logopedia: Pound, Haroldo e Ovídio

Hic puer et studiovenandilassus et aestu

Procubuit, faciemque loci fontemquesecutus.

Haroldo consegue além desse recurso em Narciso.../se inclina, a espécie de eco em "Narciso" e "seduzido" que parece querer recriar o paralelismo entre faciemque//... fontemque ausente em sua literalidade do texto de partida. Convém lembrar que o recurso logopeico de "espelhamento"13 - claro cúmulo do narcisismo! -, tanto no nível sonoro como no sintático será bastante usado em todo o texto de Ovídio. Como se não bastasse, tal qual Pound recuperara sins de possint, Campos verte lassus por "exausto" retomando sonoramente a palavra aestu que significa literalmente "verão", com o polivalente "exausto" em português, "cansado", mas também etimologicamente "sedento". O par aliterante lassus/ aestus recebe espelhamento indireto em "Da caça e do calor" que abre a sequência sintagmática do verso e que está em oposição às últimas palavras do verso seguinte "fonte amena". 0 desenho sintático é preservado, bem como a riqueza sintagmática das figuras de palavra e de pensamento, fruto da atenção do tradutor à dinâmica dos vocábulos e o seu desenho métrico.

Passemos a outro verso:

Spectathumipositusgeminum, sua lumina, sidus

(Ov. Met. 420)

De bruços, vê dois sóis, astros gêmeos, seus olhos.

A beleza logopeica aqui reside no desdobramento do sintagma geminumsidus (note-se as assonâncias em /i/ e /u/) pela inserção de sua

${ }^{13}$ Chamo de espelhamento o que, talvez mais tecnicamente, chama-se de paralelismo. Neste ponto, convém destacar a importância que Jakobson dá a essa figura de linguagem: "os sistemas paralelísticos em arte verbal nos dão uma visão direta da própria concepção dos falantes com respeito às equivalências gramaticais. [...] Fenômenos como a interação entre equivalências e discrepâncias sintáticas, morfológicas e léxicas, como os diferentes tipos de contiguidades semânticas, similaridades, sinonímias e antonímias, enfim, os diferentes tipos e funções dos chamados 'versos isolados', todos esses fenômenos estão a exigir uma análise sistemática” (1970, p.70). 
lumina (em u/a). No verso latino não está presente o vocábulo "sóis" que Haroldo insere no texto de chegada. Mas, em latim, lumina tem o sentido tanto de "luzes" quanto de "olhos", assim, o que está em jogo na inserção haroldiana é a tradução da metáfora latente em lumina por "dois sóis". A duplicação do par "dois" / "gêmeos" dá conta da dupla de adjetivo/ substantivo que em latim reencena os olhos dentro dos olhos e também olhos refletindo olhos, como tento representar minimamente abaixo

Spectathumipositusgeminum, sua lumina, sidus.

A configuração imagética aqui não deve ser confundida com a fanopeia, porque ela subsiste totalmente na sequência discursiva em latim que articula ao mesmo tempo sucessão frasal e função sintática desinencial.

Mais um verso:

Cunctaquemiratur, quibus est mirabilis ipse.

(Ov. Met. 424)

No mirar-se, admira o que nele admiram.

(Tradução do conteúdo)

"e admira tudo aquilo pelo qual ele mesmo é admirável."

Nesse verso, novamente construído pela figura do paralelismo, há o jogo ativo e passivo entre mirature mirabilis. Campos desmembra o sentido de miraturque significa ao mesmo tempo "olhar-se/mirar-se" e "admirar", conseguindo, aqui, uma reduplicação por conta do reflexivo "se" em português, o que proporciona uma interessante versão em que se amplifica os paralelismos possíveis por meio de um recurso de eco sonoro da raiz -mira-, recurso que será depois retomado ao final da passagem.

"No mirar-se, | admira | o que nele admiram" Narciso olha Narciso / Narciso (ativo) / Narciso (passivo) 
Interessante aqui é a intervenção do tradutor presente no sintagma "no mirar-se". Note-se que Narciso só irá se reconhecer no verso 463 (iste ego sum!), de modo que é irônica a inserção de "no mirar-se" pelo tradutor que atualiza o texto em chave psicanalítica. Haroldo de Campos sublinha e expande logopeia do texto de partida ao inserir na sua versão um anacronismo, neste ponto, concorde com o make it new poudiano.

Depois de um longo trecho descritivo, Narciso começa uma prece ao bosque a partir do 442. A voz apaixonada de Narciso quer convencer seu reflexo a amá-lo. No reverberar dessa interpelação, amplamente construída pelo recurso do paralelismo, há logo a partir do quinto verso da sequência, um trabalho logopeico interessante:

Et placetetvideo; sedvideoqueplacetque
Non tameninvenio; tantusteneterror amantem.

(Ov. Met. 446-7)

Vejo o que amo, mas o que amo e vejo, nunca posso tomá-lo, e em tanto erro insisto amando.

(Tradução do conteúdo) "Agrada-me e vejo, mas o que vejo e me agrada ainda não encontro, tanto engano se apodera de um amante"

Aqui Haroldo consegue equivaler os paralelismos entre placet e uideo, em que a insistente duplicação dos verbos "ver" e "amar" mimetiza a ideia do espelho das águas, mas também da loucura que já começa a tomar conta de Narciso. Porém, ao que posso ver,a grande elaboração logopeica em português está na ambiguidade da tradução "e em tanto erro insisto amando", em que se pode ler "e, entanto erro, insisto amando" ou seja, "e, apesar de errar, insisto amando" ou "e em tamanho engano insisto amando". O vocábulo error em estado de dicionário latino pode significar "sou enganado" (1.a pessoa do presente da voz passiva do v. er- 
rare), mas também o substantivo "engano" (error, erroris). Apesar de no verso ocorrer o substantivo, é muito interessante a solução de Campos, pois ele cria concretamente em português um espelhamento apenas sugerido no texto de partida. A logopeia está além das representações das letras, ela é fluxo discursivo, nada senão linguagem, e, como tal, avança para o subliminar e para o entredito.

Encaminho-me para o final deste artigo e para o final da passagem narcísica. As Metamorfoses são uma complexa e inorgânica história do mundo a partir das transformações. São, portanto, um construto metapoético e metanarrativo, uma vez que a mudança de um estado A para um estado B é a estrutura narrativa fundamental. Podemos lê-la como quem consulta uma enciclopédia, ou seja, ela desdenha da linearidade, mas é também carmendeductum, "um poema arrastado", uma longa concatenação engendrada de narrativas. ${ }^{14}$ Imediatamente anterior à passagem de Narciso tem lugar o frustrado flerte entre o jovem e a ninfa Eco. Sobre a ninfa recai a maldição impetrada por Juno de ela apenas repetir as últimas palavras que ouve. Eco é o correspondente sonoro - em termos poundianos melopeico - do paralelismo logopeico de Narciso em termos de duplo e de espelho, ou simplesmente, de eco. 0 que se pode dizer pelas últimas palavras de um discurso, o que se pode dizer pela última palavra de um verso ou daquela que incide em uma cesura? Esta é verbalmente Eco.
assim Narciso, pouco a pouco,
pela chama de amor se fina e se consome.
Sua tez não mais figura neve enrubescida, nem força, nem vigor, tudo o que à vista agrada, nada resta em seu corpo, outrora amado de Eco, a ninfa, que ao fitá-lo se condói, ferida

\footnotetext{
${ }^{14}$ A relação dessa estrutura forjada por Ovídio com experimentos de Joyce (Ulisses) e Pound (The Cantos) não escapou à leitura de Haroldo de Campos (1994, p.6-6) e à de Augusto de Campos: "a narração de índole fragmentária, alógica, atemporal, descontínua, e, portanto, econômica e ecumênica (ao contrário da narração uniforme, lógica e contínua, casuisticamente desenvolvida) se impôs - do Ulisses ao Mobile - como o método formal adequado para a mente contemporânea" (CAMPOS, A., 1978, p.192-3).
} 
VIEIRA, B. V. G. A tradução da Logopedia: Pound, Haroldo e Ovídio

embora pelo seu desprezo. A ninfa chora

e "Ai!" lhe responde aos "ais", duplica seus lamentos.

(489-496)

Nesse trecho, Haroldo investe pesadamente no trabalho melopeico, porque a ninfa rima e, assim, conjumina-se com a linha logopeica predominante.

Quaetamen ut vidit, quamvisiratamemorque, Indoluit, quotiensquepuermiserabilis "Eheu!" Dixerat, haecresonisiterabatvocibus "Eheu!"

(Ov. Met. 494-6)

a ninfa, que ao fitá-lo se condói, ferida embora pelo seu desprezo. A ninfa chora e "Ai!" lhe responde aos "ais", duplica seus lamentos.

A repetição de "ninfa”, palavra que não está presente no texto de partida, e mais, os pares "fItÁ-lo/ferIdA" e no último verso da sequência $\mathrm{AI} / \mathrm{AIs} /$ duplIcA, equivale a reiteração das vogais /e/ e / $u$ / no texto de partida, não satisfeito e com um requinte caro à logopeia, porque tradutoriamente paronomásico, Haroldo dispõe engenhosamente no eixo sintagmático as assonâncias e aliterações de "PELO DESPrEzO//... RESPONDE/SEUs lamENtOS", reconstruindo assim efeitos presentes no texto de partida presentes no homeoteleuto (porque falar em rima em latim é um despropósito) de EhEU! ao fim dos versos 495 e 496.

A sofisticada tradução de Ovídio por Haroldo é um claro testemunho da contribuição que um pensamento dinâmico entre a poesia do passado e a poesia do presente é capaz de alcançar. Quando Pound define as espécies de poesia, especialmente na definição de melopeia e logopeia, de fato não faz nada além do que a poética e retórica antigas já haviam 
abordado no nível das figuras de palavra e das figuras de sintaxe. ${ }^{15}$ No entanto, quando chama atenção à excelência dos poetas gregos e latinos como predecessores que importam ao mundo contemporâneo, porque ensinam ao poeta de hoje algo fundamental, raro e especioso em poesia, Pound consegue tirar do estudo da Antiguidade aquela sensação de inutilidade que um repertório depositado sob a poeira dos séculos poderia causar a um jovem estudante de poesia.

Assim, a tradução de $A B C$ of Reading, com o título $A B C$ da Literatura, publicada em 1970 no Brasil, sob influência dos poetas concretos, acabou por ensinar a uma nova geração de interessados em poesia que era importante ler (e traduzir) o grego e o latim, e, o que ainda é melhor!, que grego e latim, na medida em que importavam à poesia moderníssima, eram uma coisa legal (no sentido que a expressão tem ainda hoje não só para os adolescentes...). Tão importante foram- e ainda são, já que em 2010 a versão portuguesa alcançou sua 13a. edição - as ideias poundianas que o conceito de logopeia(e o de melopeia) ocupa um papel importante e decisivo na leitura e na tradução de poesia latina ainda hoje. Mas, conforme procurei formular aqui, o modo como tal conceito ainda viceja no Brasil deve-se muito às adaptações e reelaborações de Haroldo de Campos, o translatormaximus que há dez anos nos deixou.

\section{REFERÊNCIAS}

CAMPOS, A. de. Metamorfoses das Metamorfoses. In: Verso reverso controverso. São Paulo: Perspectiva, 1978. p.191-198.

CAMPOS, H. de. Crisantempo: no espaço curvo nasce um. São Paulo: Perspectiva, 1998.

\footnotetext{
${ }^{15} 0$ próprio Haroldo parece reconhecer esse vínculo das ideias de Pound com a Retórica quando define a logopeia homérica nestes termos: "a coreografia sintática dos excursos oratórios que permeiam o texto, fazendo dele, no caso da Ilíada, não apenas a encenação de feitos guerreiros, mas também o cenário de múltiplos confrontos retóricos" (CAMPOS, H., 1999, p.111).
} 
CAMPOS, H. de. Da transcriação:poética e semiótica da operação tradutora. IN: OLIVEIRA, A. C.;SANTAELLA, L.(Orgs.) Semiótica da literatura. São Paulo: EDUC, 1987. p.53-74.

. Logopeia, toques surreais, giros barroquizantes: a poesia de John Ashbery. IN: . 0 segundo arco-íris branco. São Paulo: Iluminuras, p.185-9. (publicado originalmente em Folha de São Paulo, São Paulo, 24 out. 1993. Mais!, p.6-6).

. Transcriar Homero: desafio e programa. In: ; MENDES, M. O.0s nomes e os navios: Homero, Ilíada, II. Org., introdução e notas de Trajano Vieira. Rio de Janeiro: Sette Letras, 1999.p.111-28.

. Uma metamorfose. Folha de São Paulo, São Paulo, 21 ago. 1994. Mais!, p.6-6.

.Xadrez de estrelas: percurso textual 1949-1974. São Paulo: Perspectiva,1976.

DAVIDSON, P. Ezra Pound and Roman Poetry: A Preliminary Survey. Amsterdam: Rodopi, 1995.

FLORES, G. G. Tradutibilidades em Tibulo. Scientiatraductionis, Florianópolis, n.o 10, 2011. p.141-150.

JAKOBSON, R. Linguística e comunicação. Trad. de I. Blikstein e J. P. Paes. São Paulo: Cultrix/EDUSP, 1969.

. Poesia da gramática e gramática da poesia. In: .Linguística. Poética. Cinema. São Paulo: Perspectiva, 1970. p.65-79.

LIMA, A. D. De metrificação e poesia latina. Alfa, São Paulo, v. 47(1), 2003.p.99-109 
LOPES, E. Fundamentos da linguística contemporânea. São Paulo: Cultrix, 1980.

LOY, M. The lost lunar Baedeker: poems of Mina Loy. Ed. R. L. Conover. New York: FarrarStrausGiroux, 1996.

MILTON, J. Tradução: teoria e prática.3.a ed. São Paulo: Martins Fontes, 2010.

NICHOLLS, P. 'Arid clarity': Ezra Pound, Mina Loy, and Jules Laforgue. The Yearbook of English Studies, v. 32, Children in Literature, 2002. pp. 52-64.

OVIDE. LesMétamorphoses. Trad. J. Chamonard. Paris: Garnier, 1936.

POUND, E. ABC da literatura.Trad. A. de Campos e J. P. Paes. São Paulo: Cultrix, 1970.

.Como ler. In: A arte da poesia: ensaios escolhidos. Trad. H. L. Dantas e J. P. Paes. São Paulo: Cultrix: 1976. p.25-56.

.A list of the books: "Others". The Little Review, vol. V, n. 11, mar. 1918, p.56-58.

.Literary essays of Ezra Pound.Ed. e introd. T. S. Eliot. London: Faber, 1960.

PRADO, J. B. T. Canto e encanto, o charme da poesia latina: contribuição para uma poética da expressividade em língua latina, 1997. 272 f. Tese (Doutorado em Letras Clássicas) Universidade de São Paulo.

TONETO, D. J. M. Haroldo de Campos e a utopia da escritura original. Revista FronteiraZ, vol. 9, p.175-187, 2012. 
VIEIRA, B. V. G. A tradução da Logopedia: Pound, Haroldo e Ovídio

VIEIRA, B. V. G. Contribuições de Haroldo de Campos para um programa tradutório latino-português. Terra Roxa e outras terras- Revista de Estudos Literários. Londrina, vol. 7, p.80-88, 2006. 